\title{
Traditional or Specialty Cut Flowers? Estimating U.S. Consumers' Choice of Cut Flowers at Noncalendar Occasions
}

\author{
Chengyan Yue ${ }^{1,3}$ \\ University of Minnesota-Twin Cities, Horticultural Science and Applied \\ Economics, 1970 Folwell Avenue, St. Paul, MN 55108 \\ Charles Hall ${ }^{2}$ \\ Texas A\&M University, Horticultural Sciences, College Station, TX 77843
}

Additional index words. gift giving, gift recipient, marketing, symbolic meaning

\begin{abstract}
Little research has been conducted that comprehensively studies consumers' choices of cut flowers at different occasions and for different gift recipients and how they associate different meanings with various types of cut flowers. Therefore, this article attempts to fill this gap in the literature. Using data collected by the Ipsos-National Panel Diary Group for the American Floral Endowment, we determine how the purchases of both traditional and specialty cut flowers have been changing over time and how characteristics of gift purchasers and gift recipients affect consumers' choice of different types of cut flowers. The data include consumers in 48 states and Washington, DC, whose floral purchases were tracked monthly for 14 years. Findings of this analysis confirm that floral purchases have been changing over time. In addition, the underlying drivers of floral purchases are dependent on the floral-buying occasion and the motivations underlying gift giving. These factors also influence the choice of which flowers to purchase along with the sentiment and/or symbolic meaning associated with each flower type.
\end{abstract}

Consumers typically purchase cut flowers either for their own enjoyment or to use them as gifts. Unlike many edible horticultural crops whose quality attributes can be quantified (e.g., milligrams of fiber or sugar in an apple or 1 pound of celery), consumers purchase cut flowers because of a set of aesthetic attributes that are closely connected to the occasions of the purchases. When used as gifts, cut flowers are usually purchased for a variety of reasons ranging from expressions of love or sympathy to apology or appreciation. Therefore, knowing why consumers choose different varieties of cut flowers at different occasions, who the buyers are of different cut flowers, and for whom the consumers are buying are essential to understanding the demand for different types of cut flowers.

The purchasing of different types of flowers should be substitutable to some degree even if they are differing products. The reasons for buying flowers might be similar even if the actual flowers are different. Some products may have similar attributes depend-

Received for publication 30 Nov. 2009. Accepted for publication $21 \mathrm{Jan} .2010$.

We acknowledge the generous support of the American Floral Endowment in granting access to the Consumer Tracking Study data set.

${ }^{1}$ Assistant Professor and Bachman Endowed Chair in Horticultural Marketing.

${ }^{2}$ Professor and Ellison Chair in International Floriculture.

${ }^{3}$ To whom reprint requests should be addressed; e-mail yuechy@umn.edu. ing on use of the purchase (Girapunthong and Ward, 2003). Accordingly, consumers might easily change their choices among different types of cut flowers. The purchasing behavior of consumers is also tied to many factors such as income, purchasing occasion, perceptions, relationship with recipients, and product availability. Understanding how these major factors affect consumer choices between different types of cut flowers will help the flower industry effectively meet consumer demand in addressing demand issues.

Specialty cut flowers include all decorative plant materials except roses, chrysanthemums, and carnations; the last three are often referred to as traditional cut flowers (Gast and Stevens, 1993). Specialty cut flowers include, for instance, lilies, tulips, gladioli, and Dutch iris. Specialty cut flowers were popular several decades ago but lost favor in the market as a result of short vase lives. In recent years, however, the interest in producing specialty cut flowers is rising in this country as a result of the intense competition with traditional cut flowers from overseas. Because more and more traditional cut flowers in the United States were imported from Ecuador and Columbia, many domestic cut flower growers turned to growing specialty cut flowers to remain competitive (SAF Business \& Economic Trends Committee, 2007). A consistent language of flowers is difficult to identify, but it is generally agreed that they do convey sentiment (Doyle et al., 1994). Different types of flowers convey different symbolic meanings and are used for different occasions accordingly. For example, consumers often associate roses with expressions of romantic feelings (The flower expert, 2010). A better understanding of consumers' choices of traditional cut flowers or specialty cut flowers at different occasions can provide the retail florist industry with tools to better serve their customers and expand their market potential.

Most previous research on flowers either focuses on a few specific gift-giving occasions or, at most, a few types of flowers. Shoemaker and Relf (1994) studied the attitude of recently bereaved consumers toward sympathy flowers. They found that most sympathy flowers are sent to close friends and family members and most respondents receiving sympathy flowers indicated that flowers help them deal with grief better than all other rituals associated with funerals except contact with family and friends.

Color is an important characteristic affecting consumer preference and the meaning associated with the purchase. Yue and Behe (2010) found consumers associate different cut flower colors with different calendar and noncalendar occasions. Behe et al. (1999) investigated consumers' preference for geranium flower color and leaf vegetation and found that flower color was the primary consideration in the purchase decision for geranium. Doyle et al. (1994) studied how people connected meanings with particular arrangements of flowers and found that participants reliably associated selected arrangements with particular meanings. For instance, they found that three red roses were particularly appropriate to convey the messages "I love you" and "I apologize," but three yellow carnations or three white daisy sprays inadequately conveyed these messages.

To our knowledge, there has been no research that comprehensively studies consumer choices of cut flowers at different occasions and for different gift recipients and how they associate different types of cut flowers with different meanings. Therefore, this article attempts to fill this gap in the literature. The specific objectives of our study are to determine: 1) how the purchases of traditional and specialty cut flowers have been changing over time; 2) what types of cut flowers consumers purchase at different occasions; 3 ) what symbolic meanings consumers associate with different types of flowers; and 4) how characteristics of gift purchasers and gift recipients affect consumers' choice of different types of cut flowers.

\section{Materials and Methods}

Data used in this study were collected by the Ipsos-National Panel Diary Group (NPD) for the American Floral Endowment. NPD maintained an extensive consumer panel from which the American Floral Endowment collected consumer transactions of floral products from 1992 to 2005 . These data include consumers in 48 states and Washington, DC, whose floral purchases were tracked monthly for 14 years. Demographic information about participants was recorded along with data regarding participant choices of different 
flower varieties, for whom they were purchasing, and at what occasions the purchases were made. Given the 13-year timeframe, large geographic area covered, and large sample size of the study, we consider the data representative of all consumers of floral products in United States during this time period.

The consumers' choice of flower varieties is motivated by and depends on latent degree of satisfaction they can derive from the purchase (Greene, 2002; Yue and Behe, 2008, 2010). Specifically, consumers will likely choose the flower variety that gives them the highest latent degree of satisfaction. Although satisfaction cannot be directly observed, their choice of specific flower variety can. For this analysis, we grouped flower varieties into eight categories (Table 1): carnations, roses, chrysanthemums/daises, daffodils/iris/tulips, gladiolas/snapdragons, lilies, orchids/tropicals, and other.

Because the dependent variables were categorical (eight flower categories), we used a multinomial logit model to estimate the probability of a consumer's purchase of different categories of flowers. The consumers' satisfaction derived from purchases of different types of flowers was related to certain measurable factors, including the consumers' demographic characteristics, the buying occasion, the recipients' demographic characteristics, the month and year of the purchase, and whether they purchased flowers for self-use or as gifts. The consumers' demographic characteristics included age, gender, education level, income, and household size. All dependent and explanatory variables and their summary statistics are listed in Table 2.

The maximum likelihood estimation method was used to estimate coefficients using SAS 9.1.3 (SAS Institute, Inc., Cary, $\mathrm{NC)}$. In total, 58,851 observations were used for the analysis. Some observations were not used as a result of one or more missing values.

\section{Results and Discussion}

Table 1 summarizes the cut flower categories we used in our estimation and their corresponding flower varieties. The categories (and number of corresponding observations) include: carnations, which includes cut carnations only (15,783 observations); chrysanthemums/ daisies, which includes cut chrysanthemums or cut daisies (1,294 observations); daffodils/iris/ tulips, which includes cut daffodils or cut iris or cut tulips (1,287 observations); gladioli/ snapdragons (266 observations); lilies (504 observations); orchids/tropicals (215 observations); roses (23,934 observations); and others (15,568 observations).

From Table 1 we can see that among single cut flower varieties purchased by consumers, the traditional cut flower varieties such as cut roses and cut carnations still dominate the market; cut chrysanthemums or cut daisies represent the third largest market share. Specialty cut flower varieties are still minorities in the cut flower market,
Table 1. Cut flower categories and the corresponding flowers varieties $(n=58,851)$ associated with 14 years of floral purchasing data collected by the Ipsos-National Panel Diary Group (NPD) for the American Floral Endowment.

\begin{tabular}{llr}
\hline Cut flower category & \multicolumn{1}{c}{ Description } & Number of observations \\
\hline Carnations & Cut carnations only & 15,783 \\
Chrys/Daisies & Cut chrysanthemums or cut daises & 1,294 \\
Daffs/Iris/Tulips & Cut daffodils or cut iris or cut tulips & 1,287 \\
Glads/Snaps & Cut gladioli or cut snapdragons & 266 \\
Lilies & Cut lilies & 504 \\
Orchids/Tropicals & Cut orchids or tropical cut flowers & 215 \\
Roses & Cut roses only & 23,934 \\
Other & Other single variety & 15,568 \\
\hline
\end{tabular}

Table 2. Summary statistics and descriptions of the explanatory variables $(\mathrm{n}=58,851)$ used in a multinomial logit model to estimate the probability of a consumers' purchase of different categories of cut flowers using 14 years of floral purchasing data collected by the Ipsos-National Panel Diary Group (NPD) for the American Floral Endowment.

\begin{tabular}{|c|c|c|c|}
\hline Variable & Description & Mean & SD \\
\hline \multicolumn{4}{|c|}{ Who the cut flowers were bought for } \\
\hline Parent & Bought for parents, $1=$ yes, $0=$ no & 0.103 & 0.304 \\
\hline Child & Bought for children, $1=$ yes, $0=$ no & 0.056 & 0.230 \\
\hline Spouse & Bought for spouse, $1=$ yes, $0=$ no & 0.249 & 0.432 \\
\hline Grandparent & Bought for grandparents, $1=$ yes, $0=$ no & 0.014 & 0.116 \\
\hline Self & Bought for self, $1=$ yes, $0=$ no & 0.319 & 0.466 \\
\hline Sibling & Bought for siblings, $1=$ yes, $0=$ no & 0.018 & 0.133 \\
\hline Relative & Bought for relatives, $1=$ yes, $0=$ no & 0.035 & 0.183 \\
\hline Secretary & Bought for secretaries, $1=$ yes, $0=$ no & 0.003 & 0.054 \\
\hline Significant other & Bought for significant other, $1=$ yes, $0=$ no & 0.045 & 0.208 \\
\hline Other & $\begin{array}{l}\text { Bought for other receipts except those listed, } \\
1=\text { yes, } 0=\text { no }\end{array}$ & 0.158 & 0.197 \\
\hline Whoforgender & The gender of the receivers, $1=$ male, $0=$ female & 0.049 & 0.215 \\
\hline \multicolumn{4}{|c|}{ 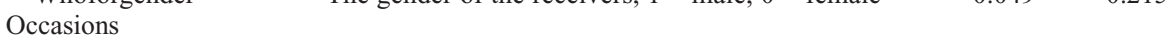 } \\
\hline Anniversary & Anniversary occasions, $1=$ yes, $0=$ no & 0.048 & 0.213 \\
\hline Birthday & Birthday occasions, $1=$ yes, $0=$ no & 0.095 & 0.293 \\
\hline Business & Business occasions, $1=$ yes, $0=$ no & 0.002 & 0.047 \\
\hline Calendar & Calendar occasions, $1=$ yes, $0=$ no & 0.190 & 0.392 \\
\hline Cemetery/memorial & Cemetery or memorial occasions, $1=$ yes, $0=$ no & 0.024 & 0.152 \\
\hline Congratulations & Congratulation occasions, $1=$ yes, $0=$ no & 0.017 & 0.128 \\
\hline Decoration & $\begin{array}{l}\text { Home decoration or homewarming occasions, } \\
1=\text { yes, } 0=\text { no }\end{array}$ & 0.044 & 0.206 \\
\hline Friendship & Friendship occasions, $1=$ yes, $0=$ no & 0.009 & 0.096 \\
\hline Get well & Get well occasions, $1=$ yes, $0=$ no & 0.034 & 0.180 \\
\hline Hostess gift & Hostess gift occasions, $1=$ yes, $0=$ no & 0.006 & 0.078 \\
\hline Sorry & To express sorry, $1=$ yes, $0=$ no & 0.008 & 0.089 \\
\hline Love & To express love, $1=$ yes, $0=$ no & 0.050 & 0.218 \\
\hline Maternity & Maternity or new birth occasions, $1=$ yes, $0=$ no & 0.008 & 0.087 \\
\hline Sympathy/funeral & To express sympathy, $1=$ yes, $0=$ no & 0.024 & 0.153 \\
\hline Thank you & To express thank you, $1=$ yes, $0=$ no & 0.016 & 0.127 \\
\hline Wedding & Wedding occasions, $1=$ yes, $0=$ no & 0.010 & 0.100 \\
\hline Other occasions & Other occasions except those listed, $1=$ yes, $0=$ no & 0.416 & 0.493 \\
\hline \multicolumn{4}{|c|}{ Participants' sociodemographics } \\
\hline Age1 & Age younger than 25 years, $1=$ yes, $0=$ no & 0.070 & 0.255 \\
\hline Age2 & Age between 25 and 39 years, $1=$ yes and $0=$ no & 0.249 & 0.432 \\
\hline Age3 & Age between 40 and 54 years, $1=$ yes and $0=$ no & 0.371 & 0.483 \\
\hline Age4 & Age 55 years and older, $1=$ yes and $0=$ no & 0.310 & 0.463 \\
\hline Female & Gender of participants', $1=$ female, $0=$ male & 0.645 & 0.478 \\
\hline EduLow & Grade school or some high school, $1=$ yes, $0=$ no & 0.032 & 0.176 \\
\hline EduMedium & High school or some college, $1=$ yes, $0=$ no & 0.542 & 0.498 \\
\hline EduHigh & College degree or postcollege, $1=$ yes, $0=$ no & 0.426 & 0.495 \\
\hline Income1 & Participants' income is $\angle \$ 25,000,1=$ yes, $0=$ no & 0.195 & 0.396 \\
\hline Income 2 & $\begin{array}{l}\text { Participants' income is } \geq \$ 25,000 \text { and }<\$ 50,000, \\
1=\text { yes, } 0=\text { no }\end{array}$ & 0.321 & 0.467 \\
\hline Income3 & $\begin{array}{l}\text { Participants' income is } \geq \$ 50,000 \text { and }<\$ 75,000, \\
1=\text { yes, } 0=\text { no }\end{array}$ & 0.227 & 0.419 \\
\hline Income4 & Participants' income is $\geq \$ 75,000,1=$ yes, $0=$ no & 0.140 & 0.347 \\
\hline \multicolumn{4}{|l|}{ Quarter and year } \\
\hline Quarter1 & First quarter, $1=$ yes, $0=$ no & 0.303 & 0.459 \\
\hline Quarter2 & Second quarter, $1=$ yes, $0=$ no & 0.278 & 0.448 \\
\hline Quarter3 & Third quarter, $1=$ yes, $0=$ no & 0.217 & 0.412 \\
\hline Quarter4 & Fourth quarter, $1=$ yes, $0=$ no & 0.202 & 0.402 \\
\hline Year & $1=1992,2=1993,0.14=2005$ & 8.486 & 3.937 \\
\hline
\end{tabular}


among which cut daffodils or cut iris or cut tulips rank among the top followed by cut lilies, cut gladioli or cut snapdragons, and cut orchids or tropical cut flowers.

Summary statistics and descriptions of the explanatory variables in the multinomial logit model are presented in Table 2, in which we can see that most of cut flowers were purchased for self-use $(31.9 \%)$ followed by for spouse $(24.9 \%)$, friends $(10.6 \%)$, parents $(10.3 \%)$, children $(5.6 \%)$, and significant others $(4.5 \%)$. Other recipients included: $5.6 \%$ for children, $3.5 \%$ for relatives, $1.8 \%$ for siblings, $1.4 \%$ for grandparents, $1.2 \%$ for business acquaintances, and $0.3 \%$ for secretaries. Most flowers were purchased for female recipients (96\%). For occasion-related gift-giving, most cut flowers (19\%) were purchased at calendar occasions such as Valentine's Day, Mother's Day, and Christmas.

The next biggest noncalendar occasion at which participants purchased cut flowers included birthdays $(9.5 \%)$ followed by expression of love $(5 \%)$, anniversaries $(4.8 \%)$, home decoration or housewarming occasions $(4.4 \%)$, get well occasions $(3.4 \%)$, cemetery or memorial occasions ( $2.4 \%)$, and sympathy or funeral occasions $(2.4 \%)$. Other specified occasions included weddings, expressions of "thank you," business occasions, friendship occasions, and expressions of "I'm sorry."

Table 2 also summarizes participants' sociodemographics. Seven percent of participants were younger than 25 years old; $24.9 \%$ were between 25 and 39 years old; $37.1 \%$ were between 40 and 54 years old; and 31\% were 55 years or older. Most purchasers of cut flowers $(65 \%)$ were female. For education level, $3.2 \%$ finished grade school or some high school; $54.2 \%$ finished high school or some college; and $42.6 \%$ got a college degree or postcollege degree.

We grouped participants' income into different categories and found that $19.5 \%$ of participants earned less than $\$ 25,000$ per year, $32.1 \%$ of participants earned between $\$ 25,000$ and $\$ 50,000$ per year, $22.7 \%$ of participants' income was between $\$ 50,000$ and $\$ 75,000$ per year, and $14 \%$ of participants earned more than $\$ 75,000$ per year.

In terms of seasonality, most of the purchases of cut flowers occurred in the first quarter of the year $(30.3 \%)$ followed by the second quarter $(27.8 \%)$, the third quarter $(21.7 \%)$, and the last quarter $(20.2 \%)$. This was expected ex ante because, as we mentioned earlier, most of the purchases of cut flowers are on calendar occasions and the first two quarters include two popular flower-related occasions: Valentine's Day and Mother's Day.

The estimation results using the multinomial logit model are presented in Table 3. The $P$ values for the likelihood ratio test and score test were all $<0.001$, which indicated a good fit of the model. The flower variety category other, which referred to other single flower varieties, was used as the reference category. That is, the coefficients of variables for different flowers types in Table 3 are relative to other (the coefficients of variables associated with other are set to zero).
Year and quarter. The significant coefficient of year for each flower category indicates that the use of these cut flower categories has been changing over time. We found that as time went on, the purchases of carnations decreased, whereas other categories increased. Among the cut flower categories other than carnations, chrysanthemums/daisies grew the fastest followed by lilies, daffodils/iris/tulips, gladioli/snapdragons, and orchids/tropicals. The purchases of roses increased over time as well but not as fast as other flower categories. We found that, compared with the third quarter of a year, consumers purchased most carnations in the fourth quarter followed by the first quarter. Consumers bought significantly more chrysanthemums/daisies in the fourth quarter compared with other times of the year.

Compared with the third quarter, consumers purchased more daffodils/iris/tulips in the other three quarters, among which the first quarter ranked the top followed by the second quarter and the fourth quarter. On the contrary, consumers bought more gladioli/snapdragons in the third quarter compared with other times. Lilies and orchids/tropicals were sold the most in the second quarter. As we expected, roses were sold mostly in the first quarter and the fourth quarter of the year because there are big calendar occasions and holidays (Valentine's Day and Christmas) in these two quarters.

Cut flower recipients. We hypothesized that consumers choose certain cut flower varieties based on who was going to be the recipient. In the estimation, we used other receivers as the base for estimation. If participants wanted to purchase cut flowers for themselves, they were most likely to choose gladioli/snapdragons followed by daffodils/ iris/tulips. They are least likely to choose orchids/tropicals followed by roses, chrysanthemums/daisies, and carnations.

If cut flowers were purchased for parents, compared with other cut flower varieties, participants were most likely to purchase daffodils/iris/tulips and they were least likely to choose roses. The coefficients for gladioli/ snapdragons and orchids/tropicals were positive but not significantly different from other as a result of large standard deviations. When participants purchased cut flowers for their children, compared with other single varieties, they were most likely to buy roses followed by carnations.

As we expected, when participants purchased cut flowers for their spouse, they were most likely to buy roses compared with other single varieties. The second choice was carnations followed by chrysanthemums/ daisies. When participants purchased flowers for their grandparents, they were most likely to choose lilies followed by daffodils/iris/tulips compared with other single flower varieties. Participants were least likely to choose chrysanthemums/daisies for their siblings followed by carnations compared with other single varieties. When participants purchased flowers for their other relatives, they were least likely to choose lilies followed by daffodils/iris/ tulips and chrysanthemums/daises compared with other single varieties.

If flowers were purchased for a secretary, daffodils/iris/tulips were the top choice followed by roses and carnations. When flowers were purchased for significant others, roses were the top choice but chrysanthemums/ daisies were the last choice compared with other varieties. Consumers purchased different types of flowers for male and female receivers. If recipients were male, chrysanthemums/ daisies were the top choice, whereas daffodils/ iris/tulips and orchids/tropicals were least likely to be chosen.

Occasions. We also estimated the possibility that participants chose different types of cut flowers based on the occasion. We included calendar occasions and a series of noncalendar occasions, using "other occasions" as the base for estimation. For calendar occasions, roses were still more likely to be purchased by consumers and orchids/tropicals were also more popular compared with other single varieties. In comparison, gladioli/ snapdragons were least likely to be bought on calendar occasions followed by chrysanthemums/daisies and daffodils/iris/tulips.

For home decoration and housewarming occasions, lilies were the top choice and participants were least likely to choose traditional cut flowers such as roses and carnations. Daffodils/iris/tulips were also not as popular as other single varieties. For anniversaries, roses were still the top choice and participants were least likely to choose chrysanthemums/daisies on this occasion.

For birthday occasions, participants were most likely to choose roses followed by daffodils/iris/tulips and they were least likely to choose chrysanthemums/daisies. For business occasions, no single cut flowers varieties were significantly purchased more or less than other single varieties.

For cemetery/memorial occasions, carnations were the top choice and participants were less likely to choose daffodils/iris/tulips and roses. Participants were more likely to choose roses, lilies, and carnations to congratulate others. Roses were the top choice to express friendship, whereas carnations were most popular for get well occasions. However, traditional cut flowers such roses and carnations were less likely to be purchased as hostess gifts compared with other types of single varieties.

As we expected, roses were the top choice when participants purchased flowers to express love, but at the same time, roses were also mostly likely to be used to say "I'm sorry" to others and were also given on maternity/new birth occasions. For sympathy/funeral occasions, chrysanthemums/daisies, daffodils/ iris/tulips, and carnations were less likely to be used compared with other single varieties. Participants used carnations the most to express "thank you." For weddings, lilies and roses were the top choices and participants were least likely to choose carnations at this specific occasion.

Purchasers' sociodemographics. The sociodemographic characteristics of flower 


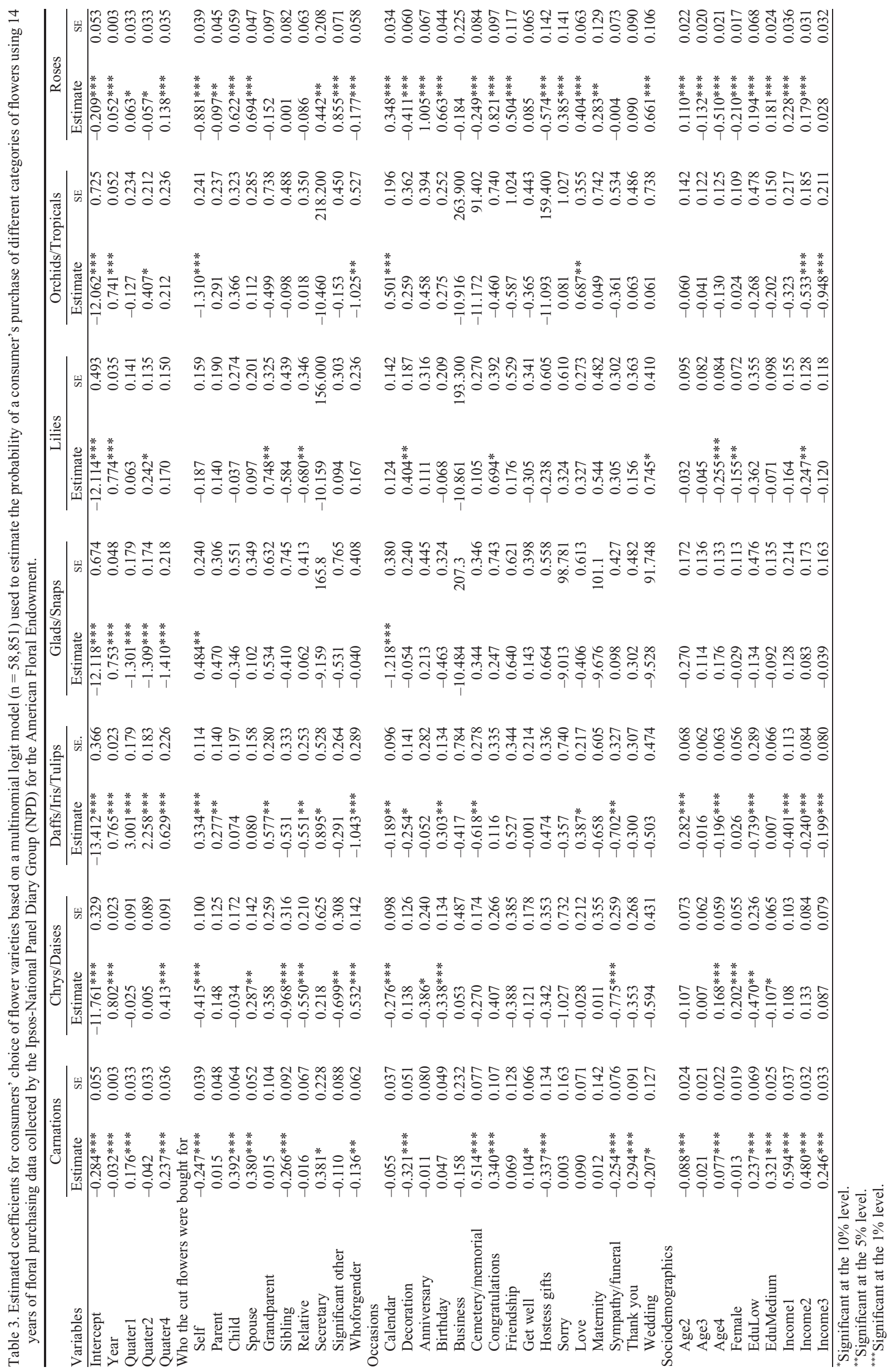


purchasers also affected their choice of different categories of cut flowers. For example, the participants' age was a major factor that determined their choice of flower varieties ( 25 years and younger were used as the base for estimation). Compared with other age categories, participants who were 55 years and older were most likely to purchase carnations and chrysanthemums/daisies, but they were least likely to purchase roses, and they were also less likely to purchase lilies and daffodils/iris/tulips. Participants who were between 25 and 39 years old were most likely to purchase daffodils/iris/tulips and roses and they were less likely to purchase carnations compared with other age groups. Although participants who were between 40 and 54 years old were less likely to purchase roses, they did not differ significantly in the choices of other flower varieties compared with the youngest age group.

Compared with male purchasers, female participants were more likely to purchase chrysanthemums/daisies, and they were less likely to purchase roses and lilies. Participants' education level affected their choice of flowers categories as well. When we used college degree or postcollege degree as the base for estimation, we found that compared with the highest education level, participants with a lower education level were more likely to purchase carnations and roses and the participants who finished some high school were less likely to purchase daffodils/iris/tulips.

Participants' income level also affected their choice of flower categories. We used highest income level as the base for estimation and found that participants with lower income level were more likely to purchase carnations and they were less likely to purchase daffodils/iris/tulips. Participants who earned less than $\$ 50,000$ per year were more likely to purchase roses compared with those who earned more than $\$ 75,000$ per year. Participants who earned between $\$ 25,000$ and $\$ 75,000$ were less likely to purchase orchids/tropicals compared with the participants in the wealthiest income category. Participants who earned between $\$ 25,000$ and $\$ 50,000$ were also less likely to purchase lilies compared with participants with the highest income category.

\section{Summary and Conclusions}

We conducted a comprehensive study on consumers' choices of cut flowers at different occasions and for different gift recipients and how they associate different types of cut flowers with different meanings. We used the data collected by the NPD for the American Floral Endowment, which was considered to represent the U.S. population.

Historically, the purchases of carnations have been decreasing, whereas other cate- gories had been increasing. In particular, specialty cut flower varieties expanded the cut flower market between 1992 and 2005 . Roses were sold mostly in the first and last quarters of the year because there are big calendar occasions and holidays (Valentine's Day and Christmas) in these two quarters. However, among single cut flower varieties purchased by consumers, the traditional cut flower varieties such as cut roses and cut carnations still dominate the market over the 14-year period; cut chrysanthemums or cut daisies represent the third largest market share. The purchases of specialty cut flower varieties such as cut daffodils or cut iris or cut tulips, cut lilies, cut gladioli or cut snapdragons, and cut orchids or tropical cut flowers are still minor compared with the traditional cut flowers in the cut flowers market.

We found that the consumers' demographic characteristics (including age, gender, education level, income, household size) affected consumers' choice of cut flower types. Participants' age was a major factor that determined their choice of flower varieties as was their education and income levels. We found that older consumers who were 55 years and older were likely to buy the two types of traditional cut flowers (carnations and chrysanthemums/daisies) and they were less likely to buy Lilies and daffodils/iris/ tulips but they were less likely to buy roses; compared with the highest education level, participants with a lower education level were more likely to purchase carnations and roses and the participants who finished some high school were less likely to purchase daffodils/iris/tulips. Participants with lower income level were more likely to purchase carnations and they were less likely to purchase daffodils/iris/tulips. Our analysis also shows that the buying occasion greatly influences the choice of flowers purchased. For calendar occasions, roses were still more likely to be purchased by consumers and orchids/tropicals were also more popular compared with other single varieties.

Our findings have important implications for cut flower businesses when deciding which types of flowers to carry and promote at different occasions. For example, depending on the sociodemographic characteristics of a firm's target market, different cut flower types should be sourced and marketed aggressively to tailor to consumers' needs and wants. In recent years, because more and more traditional cut flowers in the United States were imported from other countries such as Ecuador and Columbia as a result of the favorable weather conditions and lower labor cost, domestic cut flower growers turned to growing specialty cut flowers (SAF Business \& Economic Trends Committee, 2007). The fact that the three traditional cut flowers are still dominating the U.S. cut flower market is a challenge for U.S. cut flower growers. To survive, U.S. growers need to develop creative marketing strategies to enlarge the market for domestic specialty cut flowers. Because recent studies have found that consumers like novel flowers (Gagliardi and Brand, 2007), domestic growers can market specialty cut flowers as "special" and something "unique" to stimulate consumers' interest.

Specialty cut flower growers can also use these findings in selecting the target market on which they should focus. For instance, the target market for orchids/tropicals should be the consumers with higher income levels and the target market for daffodils/iris/tulips should be younger consumers with higher income and education levels.

For some risk-averse consumers, unfamiliarity can be a reason that has prevented them from choosing specialty cut flowers. Through educational programs and media advertisements, the floral industry can educate consumers about the symbolic meanings of specialty cut flowers, how to care for them to increase their longevity, and the proper occasions to use them.

\section{Literature Cited}

Behe, B., R. Nelson, S. Barton, C. Hall, C.D. Safley, and S. Turner. 1999. Consumer preferences for geranium flower color, leaf variegation, and price. HortScience 34:740-742.

Doyle, K.O., A. Hanchek, and J. McGrew. 1994. Communication in the language of flowers. HortTechnology 4:211-216.

Gagliardi, J.A. and M.H. Brand. 2007. Connecticut nursery and landscape industry preferences for solutions to the sale and use of invasive plants. HortTechnology 17:39-45.

Gast, K. and A. Stevens. 1993. Consumer acceptance of specialty cut flowers. HortScience 28:565.

Girapunthong, N. and R.W. Ward. 2003. Demand drivers for fresh-cut flowers and their substitutes: An application of household expenditure allocation models. Selected paper of American Agricultural Economics Association 2003 Annual Meetings, Montreal, Canada. In: Greene, W.H. 2002. Econometric analysis. 5th Ed. Prentice-Hall, Upper Saddle River, NJ.

SAF Business \& Economic Trends Committee. 2007. The changing floriculture industry: A statistical overview. 4th Ed. Society of American Florists, Alexandria, VA.

Shoemaker, C.A. and P.D. Relf. 1994. Attitudes of consumers and recently bereaved toward sympathy flowers. HortScience 29:914-915.

The flower expert. 2010. 18 Jan. 2010.<http://www. theflowerexpert.com/content/aboutflowers/ flowermeanings/rose-flower-meanings $>$.

Yue, C. and B.K. Behe. 2008. Estimating U.S. consumers' choice of floral retail outlets. HortScience 43:764-769.

Yue, C. and B.K. Behe. 2010. Consumers' preference for cut-flower color on calendar and non-calendar occasions. HortScience 45:7882. 